\title{
THERMOELASTIC ANALYSIS OF ENHANCED GEOTHERMAL SYSTEMS USING A FULLY COUPLED THERMO-HYDRO- MECHANICAL MODEL
}

\author{
MUSA D. ALIYU \\ Department of Engineering Science, the University of Auckland, Private Bag 92019, Auckland, 1142, \\ New Zealand \\ e-mail: musa.aliyu@auckland.ac.nz,web page: http://www.auckland.ac.nz
}

Key words: Enhanced Geothermal Systems, Thermoelastic Effect, Thermo-Hydro-Mechanical Model, Coupled Processes, 3D Numerical Model.

\begin{abstract}
In analysing energy extraction from enhanced geothermal systems (EGS), the thermoelastic effect on characteristic reservoir conditions must be considered. During heat extraction, thermal contraction is induced by cold fluid injection. As a result, thermoelastic deformation is triggered. The induced thermoelasticity could alter the rock's properties, such as fracture aperture and permeability, making the thermoelastic effect crucial in understanding EGS reservoir behaviour. Based on coupled thermo-hydro-mechanical (THM) processes extended to include the thermoelastic effect, this paper presents a three-dimensional (3D) numerical model of an EGS reservoir with multiple fractures. The fracture network system is the primary flow path because the surrounding rock matrix is considered impermeable [6]. The behaviour of the reservoir is studied using different flow boundary conditions. An in-depth analysis is performed to determine the rate at which the thermoelastic effect develops during heat extraction. An application of the analysis is made to investigate a reservoir's characterisation in a different range of scenarios. The results presented have shown the limitations imposed by the thermoelastic effect on the long-term performance of EGS reservoirs.
\end{abstract}

\section{INTRODUCTION}

The extraction of thermal energy from hot dry rock (HDR) geothermal reservoirs could be a significant renewable energy source in the twenty-first century. Thermal energy is extracted from HDR systems by pumping fluid via an injection wellbore to open pre-existing natural fractures in the crystalline rock to create a reservoir. After that, fluid is circulated through the fracture networks to become heated and recovered via a production wellbore [1]. Considerable effort was made in 1974 at Fenton Hill, New Mexico, to determine the feasibility of extracting energy from these systems [2]-[4]. A generalised definition was more recently adopted as engineered geothermal systems (EGS) because it was later discovered that some of the early projects did not align with the ideal description of an HDR system as initially proposed [5]-[9].

Studying the feasibility of extracting energy from EGS reservoirs is crucial to understanding the phenomena that lead to faster temperature drawdown [10], [11]. Injecting cold fluid and producing hot fluid or steam from EGS reservoirs results in thermally contracting the system, 
which induces thermoelastic deformation. The thermoelastic effect is deemed likely to increase the system's fracture apertures and affect the permeability distribution and reservoir performance. Therefore, there is a need to consider the prolonged impact of thermoelasticity on the EGS system's behaviour during long-term exploitation.

Several attempts have been made to model the thermoelastic effect of the EGS reservoir since the 1980s. Among the early models was the work of Sekine and Mura [12], who developed a two-dimensional (2D) solution to investigate the behaviour of a penny-shaped reservoir in the various stages of effective operation as a geothermal energy system. The model is implemented from the viewpoint of fracture mechanics extended to include thermoelastic effects. Abe et al. [13] further improved Sekine and Mura's model based on the 2D theory of quasi-static thermoelasticity.

In the 1990s, Hick et al. [14] incorporated the thermoelastic effect in the HOTGRID model to study the long-term performance of HDR geothermal reservoirs. HOTGRID is a 2D finite element (FE) package that solves the coupled interactions of the fluid flow, thermal and mechanical processes of HDR systems. Further, in 2006, McDermott et al. [15] developed a 3D numerical/model of the Bad Urach EGS reservoir, implementing the thermoelastic effect to analyse its long-term performance. The model fully couples mechanical deformation, fluid flow, and thermal and salinity-dependant fluid parameter function effects. They examined the thermal energy, permeability, and fluid properties response to induced thermal stress and the impact on the long-term performance of EGS reservoirs.

Recently, Jing et

application using a 3D reservoirs. The model reservoir, using the $\mathrm{Hij}$ performed to analyse the injection pressure during long-term exploitati
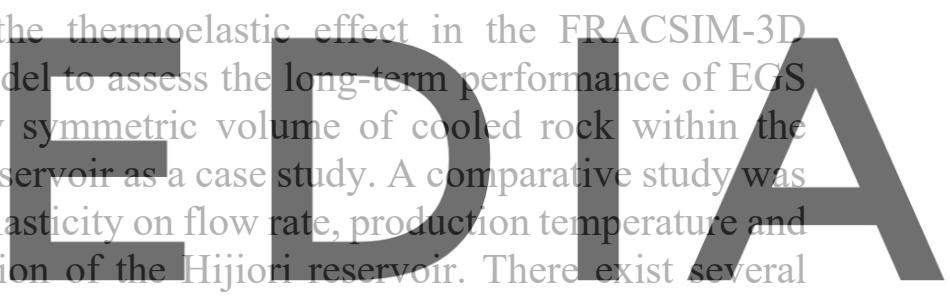
studies in the literature concerning modelling the thermoelastic effect on EGS performance.

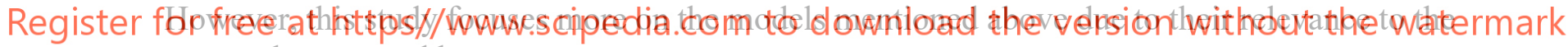
approach presented here.

The McDermott et al. [15] modelling approach is simplistic because the fracture network is approximated as an equivalent medium. On the other hand, the Jing et al. [16] model is considered complex due to the explicit representation of the stochastic discrete fractures. In order to bridge the gap between these two models, this study adopted an intermediate approach that is neither simplistic nor complex to investigate the influence of thermoelasticity on EGS performance. Thus, a 3D numerical model of multiple planar fractures in an EGS reservoir is developed, using fully coupled THM processes incorporating the thermoelastic effect. The model is implemented in the COMSOL Multiphysics FE solver to understand the role thermoelasticity plays during the long-term exploitation of EGS reservoirs. The study aims to quantify and assess induced thermal stress on fundamental reservoir parameters and the overall effect on EGS productivity.

\section{GOVERNING EQUATIONS}

The mathematical descriptions defining the behaviour of an EGS reservoir are the 
conservation laws of mass, energy, and momentum [17]. Each of the laws is combined with a specific constitutive model to represent the reservoir's behaviour properly. For example, the conservation of mass is combined with Darcy's model; energy conservation law is linked with Fourier's model; Hooke's law is combined with the conservation law of momentum [18]-[20]. Thus, the remainder of this section will present the sets of equations for the rock matrix and the fracture system relevant to thermoelasticity, and the other equations can be found in these references [21], [22].

\subsection{Mechanical deformation equations for rock matrix}

The equations describing mechanical deformation in a porous medium can be obtained by combining the linear momentum equation with Hooke's law. The porous medium is assumed to be linearly elastic, homogenous, and isotropic. Thus, the static-equilibrium equation is expressed as [23]

$$
\nabla \sigma_{i j}+F=0
$$

where $\sigma_{i j}$ is the total stress tensor and $F$ is the body or external force. The stress-strain constitutive relation is written as

$$
\sigma_{i j}=2 G \varepsilon_{i j}+\chi \varepsilon_{k k} \delta_{i j}-\frac{\alpha E \Delta T}{1-2 v} \delta_{i j}
$$
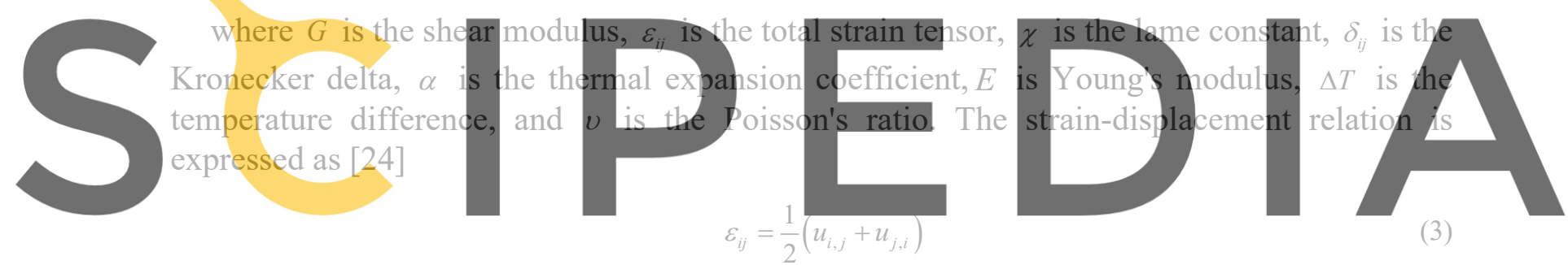

(3)

Register for free at https//www scipediancom to sownlead the versign without the watermark expression

$$
\sigma_{i j}=G \nabla^{2} u_{i}+(\chi+G) u_{j, j j}-\frac{\alpha E}{1-2 v} \nabla T
$$

Substituting (4) into (1) gives the expression describing the rock matrix deformation with its corresponding stress distribution

$$
G \nabla^{2} u_{i}+(\chi+G) u_{j, j j}-\frac{\alpha E}{1-2 v} \nabla T+F=0
$$

\subsection{Fracture aperture deformation equations}

When fluid flows in the fracture, the surfaces are held apart by internal fluid pressure, $p$. The effective stress at the surface of the fracture is given as [25], [26]

$$
\sigma_{n}^{\prime}=\sigma_{n}-\alpha_{b} p
$$


where $\sigma_{n}$ is the normal stress acting on the fracture, $\sigma_{n}^{\prime}$ is the effective stress acting on the fracture, $\alpha_{b}$ is the Biot's coefficient, and $p$ is the pore pressure. The fracture aperture $b$ under normal loading is expressed as

$$
b=b_{0}-u_{n}
$$

where $b_{0}$ is the initial fracture aperture, $u_{n}$ is the fracture normal displacement (negative denoting closure) given as [27]

$$
u_{n}=\frac{\sigma_{n}^{\prime}}{K_{n}+\frac{\sigma_{n}^{\prime}}{b_{\max }}}
$$

where $b_{\max }$ is the maximum aperture closure and $K_{n}$ is the fracture normal stiffness expressed as [27], [28]

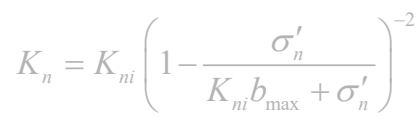

where $K_{n i}$ is the initial fracture stiffness. Substituting (8) into (7) yields the expression for fracture aperture variation

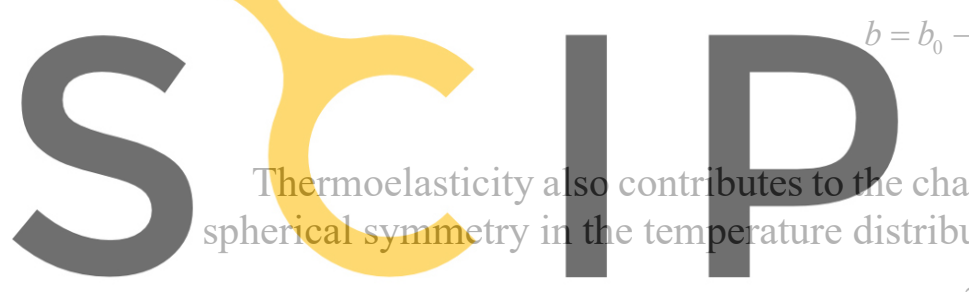

$\sigma_{T}=\frac{2 \alpha E}{3(1-v)}\left(T_{0}-T\right)$

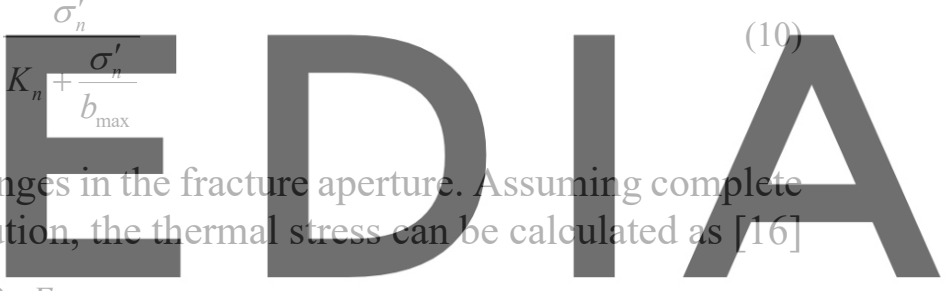

(11)

Register for free at https//www.scipedia.com to do bunload the version without the watermark

where $T_{0}$ is the initial rock temperature. Substituting (11) into (6) yields

$$
\sigma_{n}^{\prime}=\sigma_{n}-\left(p+\sigma_{T}\right)
$$

Expression (12) is the effective stress across the fracture relating to normal stress, pore pressure and thermal stress.

The fully coupled THM model has been previously implemented in the COMSOL Multiphysics solver and validated against a real-life field measurement of the Fenton Hill EGS reservoir [29], [30]. The results obtained confirm and illustrate the viability and validity of the COMSOL solver in predicting the behaviour of EGS reservoirs.

\section{MODEL DESCRPTION AND CONFIGURATION}

Figure 1 presents the geometry of the EGS reservoir with a multiple planar fracture system. The reservoir dimensions are $900 \mathrm{~m} \times 900 \mathrm{~m} \times 900 \mathrm{~m}$, with multiple fractures spaced at $100 \mathrm{~m}$ apart, each fracture has a uniform radius of $350 \mathrm{~m}$. A total of seven fractures are implemented in the model, beginning with a fracture located at the centre of the reservoir (i.e. $450 \mathrm{~m}$ [x-axis]) 
and the remaining spreading towards the front and the back of the reservoir to maintain uniformity. The wellbores have a horizontal length of $750 \mathrm{~m}$ with the injection wellbore located at $450 \mathrm{~m}$ (y-axis) and $-5,000 \mathrm{~m}$ (z-axis); and the production well is positioned at $450 \mathrm{~m}$ (ycoordinate) and $-4,500 \mathrm{~m}$ (z-coordinate), making the wellbore separation distance $500 \mathrm{~m}$. The reservoir properties employed for the study are shown in Table 1.

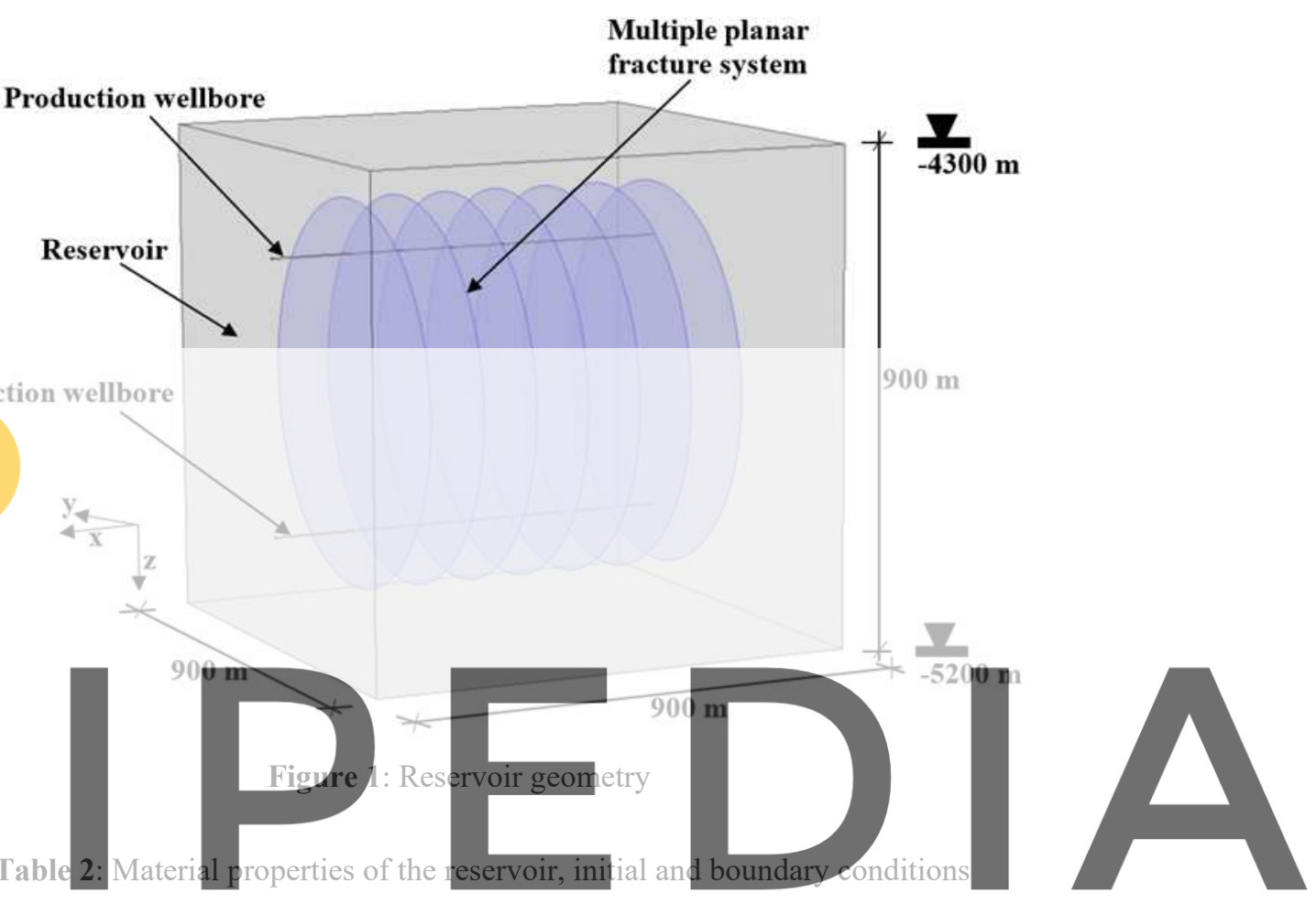

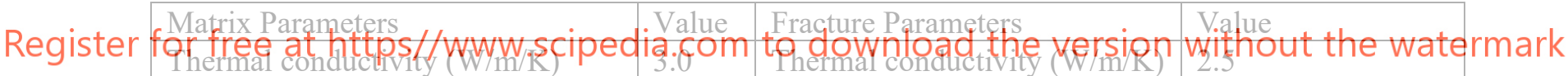

\begin{tabular}{|l|l|l|l|}
\hline $\begin{array}{l}\text { Thermal expansion coefficient } \\
(\mathbf{1} / \mathrm{K})\end{array}$ & $7 \mathrm{e}-6$ & Heat capacity $(\mathrm{J} / \mathrm{kg} / \mathrm{K})$ & 900 \\
\hline
\end{tabular}

\begin{tabular}{|l|l|l|l|}
\hline Heat capacity $(\mathrm{J} / \mathrm{kg} / \mathrm{K})$ & 900 & Fracture density $\left(\mathrm{kg} / \mathrm{m}^{3}\right)$ & 2500 \\
\hline Rock density $\left(\mathrm{kg} / \mathrm{m}^{3}\right)$ & 2700 & Young's modulus $(\mathrm{GPa})$ & 50 \\
\hline Young's modulus $(\mathrm{GPa})$ & 60 & Porosity & 0.01 \\
\hline Poison's ratio & 0.25 & Initial aperture $(\mathrm{mm})$ & 0.2 \\
\hline Porosity & 0.1 & Maximum closure $(\mathrm{mm})$ & 0.02 \\
\hline Permeability $\left(\mathrm{m}^{2}\right)$ & $1 \mathrm{e}-18$ & Initial stiffness $(\mathrm{MPa} / \mathrm{m})$ & $1 \mathrm{e} 5$ \\
\hline Vertical stress $(\mathrm{MPa})$ & 90 & Initial pressure $(\mathrm{MPa})$ & $\rho_{L} \times g \times z$ \\
\hline Maximum horizontal stress $(\mathrm{MPa})$ & 80 & Initial temperature $T_{0}(\mathrm{~K})$ & $12^{\circ} \mathrm{C}-0.04[\mathrm{~K} / \mathrm{m}] \times z$ \\
\hline Minimum horizontal stress $(\mathrm{MPa})$ & 60 & Injection pressure $p_{i n j}(\mathrm{MPa})$ & 15 \\
\hline Biot coefficient & 0.79 & Injection temperature $T_{i n j}\left({ }^{\circ} \mathrm{C}\right)$ & 40 \\
\hline Biot modulus $(\mathrm{MPa})$ & $1.23 \mathrm{e} 4$ & Thermal energy & $\dot{m} C_{P, L}\left(T-T_{i n j}\right)$ \\
\hline Solid bulk modulus $(\mathrm{GPa})$ & 50 & Production pressure $(\mathrm{MPa})$ & 2.5 \\
\hline
\end{tabular}

For the mechanical condition, initial stress equal to three stress components is added to the 
pore pressure for vertical, maximum, and minimum horizontal directions. Roller boundary supports are assigned on all sides except the top, where the vertical stress component is applied. The equations, the coupled THM processes implemented, material properties and the initial and boundary conditions presented are solved in the COMSOL Multiphysics software to obtain the simulation results provided below.

\section{RESULTS AND ANALYSIS}

The fluid injection causes the aperture to propagate, enhancing the permeability under applied pressure and cooling, as shown in Figures 2 and 3. It can be seen that a cold fluid injection causes the fracture surfaces to cool, resulting in a broader fracture aperture opening and increasing the permeability. However, as the circulation operations continue their effect declines rapidly. Continued cold fluid circulation tends to increase the pore pressure inside the rock, thus reducing the fracture aperture and permeability to some extent after five years for the thermoelastic case; and ten years in the other case.

In the long term, thermally induced stress resulting from heat production could also influence reservoir fluid-flow conditions. The fluid volume storage will increase because of thermal contraction. To some extent, the process could account for reservoir volume growth. As the fractures and the surrounding rock cools, the aperture openings increase and additional flow paths between the injector and the producer can carry increasing proportions of the total flow. The flow channelling effect could result in rapid cooling of the extraction fluid, reducing the

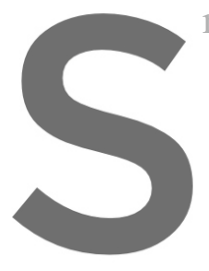
reservoir performanc
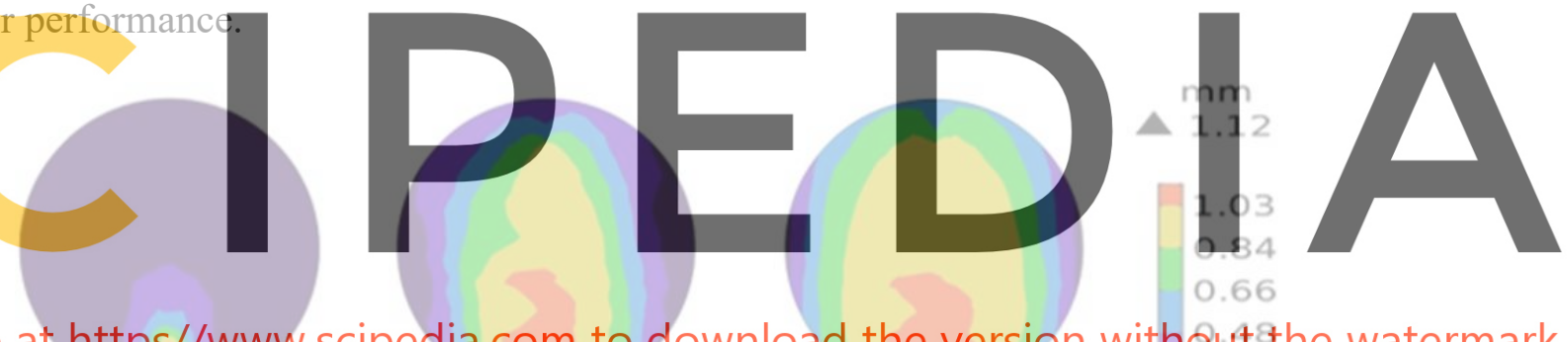

Register for free at https//www.scipedia.com to download the version with 8 utthe watermark
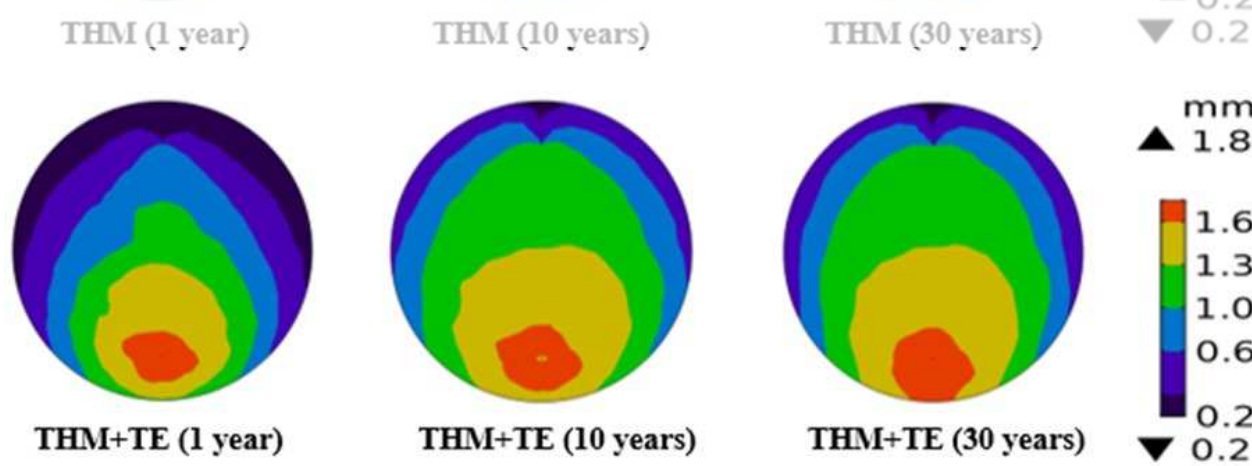

$\mathrm{mm}$

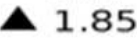

Figure 2: Middle fracture aperture evolution contours at 1 year, 10 and 30 years for the THM model with and without thermoelastic effect

Figure 4 shows the pressure evolution on the middle fracture surface of the two cases. As can be seen, the fracture's fluid pressure tends to increase with time for the scenario without the thermoelastic effect. On the other hand, as thermal stress is a dominating mechanism for the 
thermoelastic case, the pressure evolution is slow and negligible in comparison. This can be explained by recalling that cold fluid injection-induced thermal contraction on the surrounding rock matrix and the fracture surfaces results in relatively large thermal and compressive stresses; therefore, the pressure decreases [31].

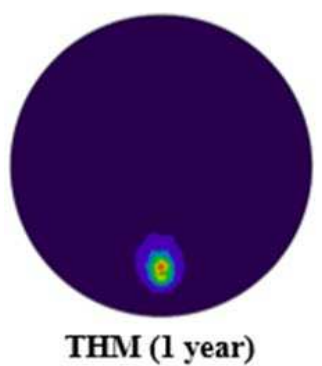

THM (1 year)

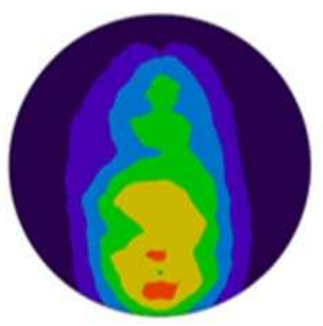

THM (10 years)

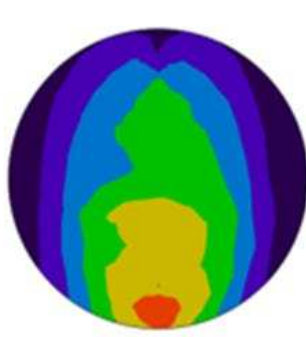

THM (30 years) $\mathrm{m}^{2}$

$\Delta \underset{\times 10^{-15}}{1.01} \times 10^{-12}$

$\times 10^{-15}$

905.99

705.93

505.88

305.82

5.73

$5.73 \times 10^{-15}$

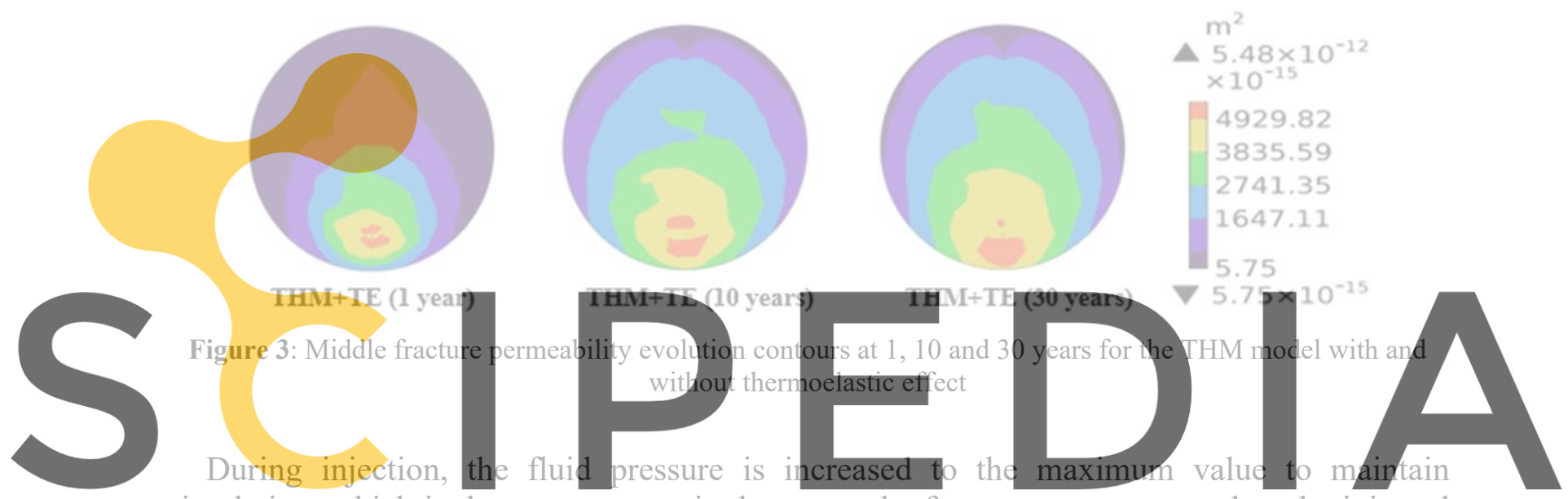

circulation, which is the pressure required to open the fractures to accommodate the injected

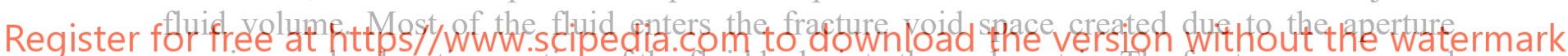
opening, and only a tiny portion of the fluid leaks into the rock matrix. The fractures are opened mechanically around the injection wellbore, making the reservoir flow rate increase with fluid pressure [32]. The constant injection pressure causes a progressive decline in the pressure, which drops across the reservoir throughout the circulation.

Figure 5 shows temperature contours for both cases, which had constant pressure boundary conditions. For the thermoelastic case, at one year, cooling occurs predominately near the injection location. At 10 years, cooling has progressed along the surface of the fracture to reach the production wellbore. After the thermal front reached the producer, the short-circuiting effect begins to intensify and progress rapidly. After that, the fluid flows through the fractures without being significantly heated by the rock matrix. For the scenario without the thermoelastic effect, the cooling is negligible at one year, affecting a tiny fraction of the injection location. After that, the cooling continues to propagate stably until much of the surrounding rock matrix's heat has been extracted.

As the thermal front advances in the fracture system, the system experiences thermal contraction. This thermal contraction effect is related to the aperture and permeability of the fractures, as discussed earlier. The increasing thermal contraction increased the aperture opening and the permeability due to reduced effective stress across the fractures. 


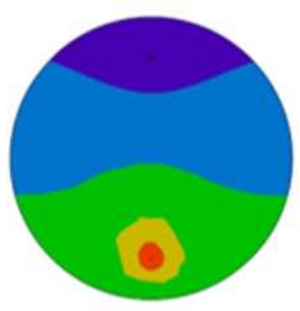

THM (1 year)

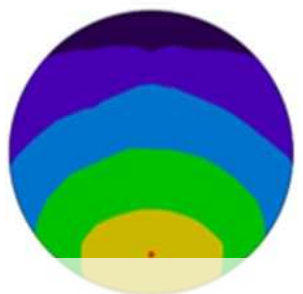

THM+TE (1 year)
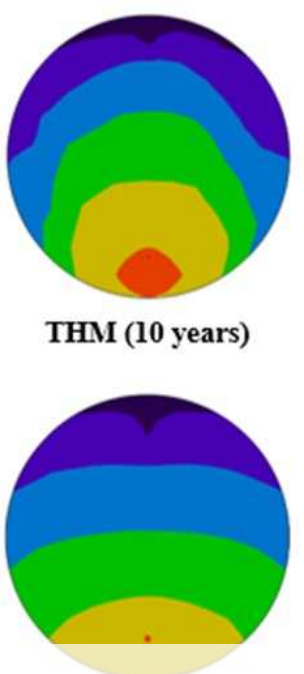

THM+TE (10 years)

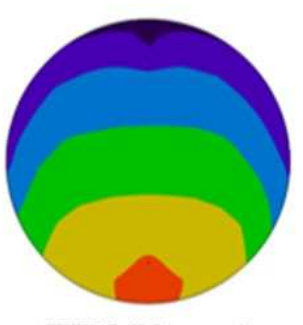

THM ( 30 years)

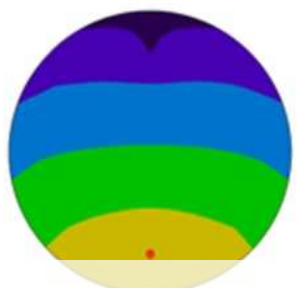

THM+TE (30 years)
$\mathrm{MPa}$

A 58.5

56.76

53.27

49.78

46.29

41.05

41.1

$\mathrm{MPa}$

- 58.5

56.84

53.52

50.19

46.87

41.89

$\nabla 41.9$

Figure 4: Middle fracture pore pressure evolution contours at 1, 10 and 30 years for the THM model with and without thermoelastic effect
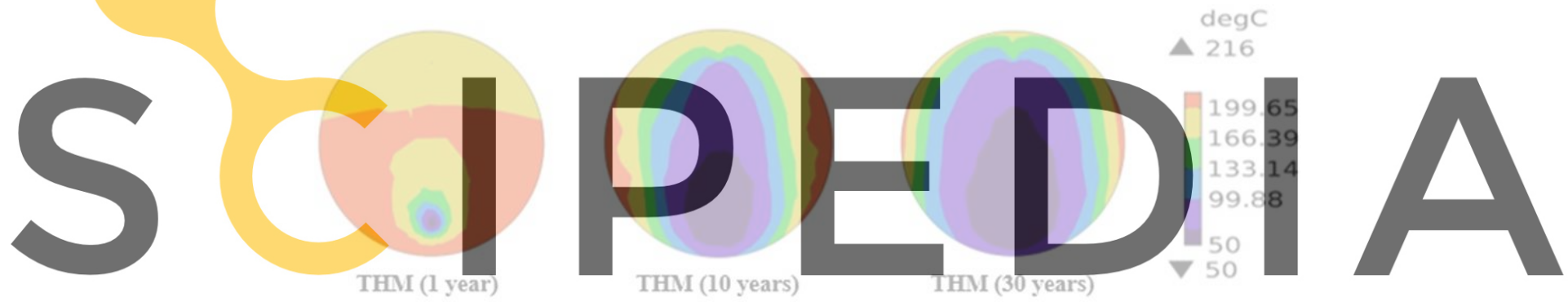

Register for free at https//www.scipedia.com to download the version withøut the watermark
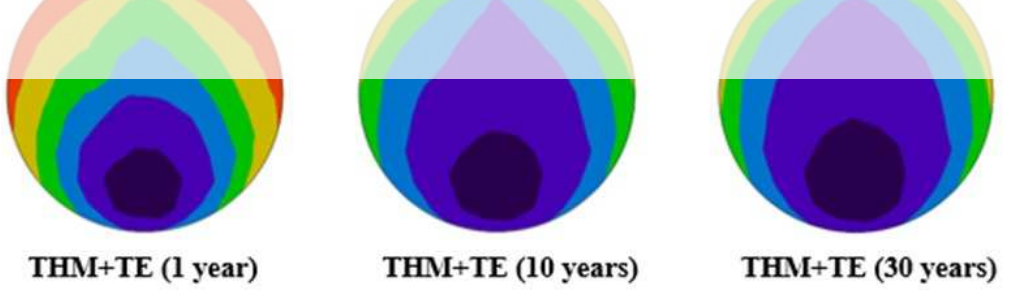

A 196

Figure 5: Middle fracture thermal front evolution contours at 1, 10 and 30 years for the THM model with and without thermoelastic effect

Figures 6 and 7 show the production temperature and thermal energy curves for the THM model, with and without thermoelastic effect. A more rapid drawdown is seen in the production temperature and thermal energy for the case with the thermoelastic effect due to induced thermal stress resulting from rock thermal contraction. The result indicates that the thermoelastic effect has a significant effect on reservoir productivity. The production temperature and thermal energy continuously decrease following the early thermal breakthrough resulting from thermal contraction. This example illustrates that our THM model 
captures the effect of thermoelastic deformation, described in Section 2, with high accuracy.

The shorter distance between the injection and production wellbores appears to have caused more fluid to flow through the fracture systems due to thermoelastic deformation, yielding faster cooling of the reservoir, resulting in a more considerable drawdown in the production temperature and thermal energy (Figures 6 and 7). Thus, the production wellbore flow rate becomes more extensive and significant because of the induced thermoelastic deformation, making the surfaces near the wellbore cooler until a stable simulation is reached.

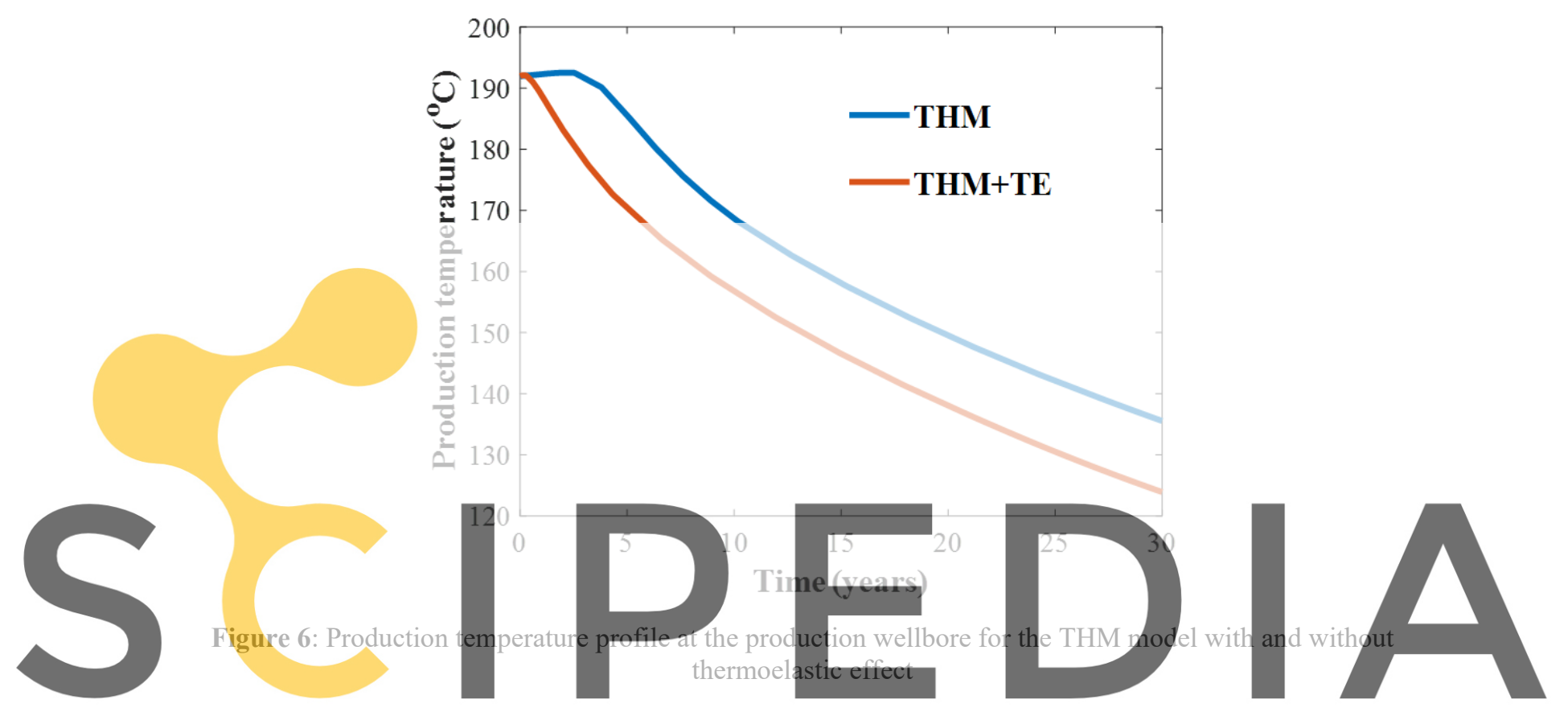

Register for free at https//www.scipedia.com to download the version without the watermark

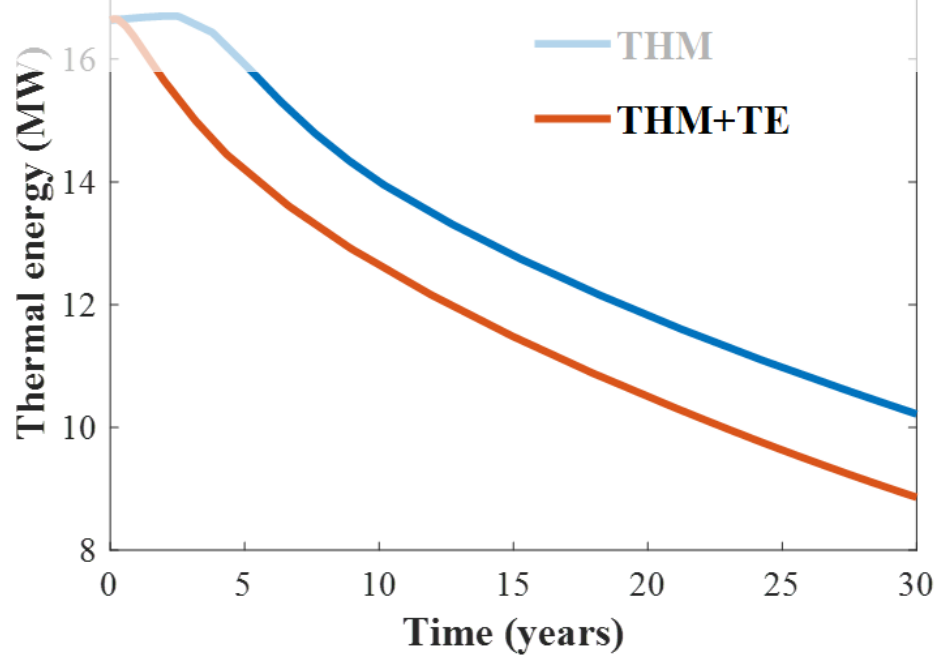

Figure 7: Thermal energy profile at the production wellbore for the THM model with and without thermoelastic effect 


\section{CONCLUSIONS}

This paper has presented a coupled THM model of a multiple planar fracture EGS reservoir, which accounts for the thermoelastic effect, to investigate the system's long-term performance. One set of study is performed: a comparative analysis of several reservoir parameter changes to exploitation between THM models with and without thermoelasticity. The results have shown that thermoelasticity greatly influences EGS reservoirs performance by increasing the fracture aperture opening, enhancing the fracture permeability, and increasing the system flow rate. Based on the comparative study conducted, it is evident that thermoelasticity must be incorporated into the THM models of EGS reservoirs to implement the coupled processes fully. By not considering the thermoelastic effect in EGS reservoirs, simulation could result in simplifying crucial aspects that have an impact on overall reservoir productivity

\section{REFERENCES}

[1] J. Willis-Richards and T. Wallroth, "Approaches to the modelling of hdr reservoirs: A review," Geothermics, vol. 24, no. 3, pp. 307-332, Jun. 1995, doi: 10.1016/03756505(95)00011-E.

[2] H. Murphy, R. Drake, J. Tester, and G. Zyvoloski, "Economics of a conceptual 75 MW hot dry rock geothermal electric power-station," Geothermics, vol. 14, no. 2-3, pp. 459-474, Jan. 1985, doi: 10.1016/0375-6505(85)90083-5.

[3] M. D. Aliyu and H. P. Chen, "Sensitivity analysis of deep geothermal reservoir: Effect of reservoir parameters on production tomper
2017 , doi: 10.1016/j. energy.2017.04.091.
D. W. Brown, D. V. Duchane, G.Heiken,
Dry. Rock Geothermal Energy, First Edit.
2012.
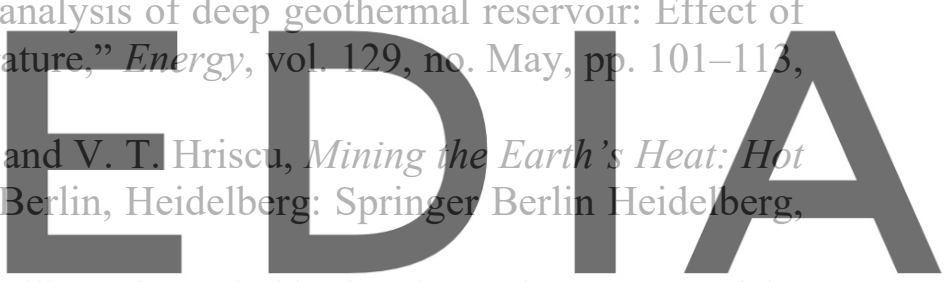

[5] M. D. Aliyu and H. Chen, "Numerical modelling of coupled hydro-thermal processes of the

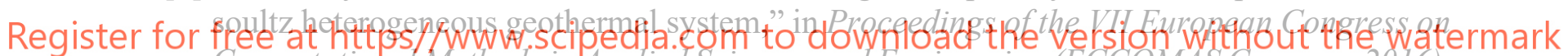
Computational Methods in Applied Sciences and Engineering (ECCOMAS Congress 2016), 2016, no. June, pp. 1659-1671, doi: 10.7712/100016.1913.9294.

[6] C. Zhang et al., "Parametric study of the production performance of an enhanced geothermal system: A case study at the Qiabuqia geothermal area, northeast Tibetan plateau," Renew. Energy, vol. 132, pp. 959-978, 2019, doi: 10.1016/j.renene.2018.08.061.

[7] X. Song et al., "Numerical simulation of heat extraction performance in enhanced geothermal system with multilateral wells," Appl. Energy, vol. 218, no. March, pp. 325337, 2018, doi: 10.1016/j.apenergy.2018.02.172.

[8] M. D. Aliyu and H. Chen, "Numerical modelling of geothermal reservoirs using the triple porosity-permeability approach," in Proceedings of the 25th UKACM Conference on Computational Mechanics 12 -13 April 2017, University of Birmingham, Birmingham, United Kingdom, 2017, no. April, pp. 10-13.

[9] M. D. Aliyu, H. Chen, C. D. HILLS, and O. Harireche, "A Fully-coupled model of heat and fluid flow in discretely fractured geothermal reservoir," in 15th UK HEAT TRANSFER CONFERENCE, UKHTC2017, Brunel University London, 4-5 September 2017, 2017, no. September, pp. 1-2. 
[10] M. D. Aliyu and H.-P. Chen, "Enhanced geothermal system modelling with multiple pore media: Thermo-hydraulic coupled processes," Energy, vol. 165, pp. 931-948, Dec. 2018, doi: 10.1016/j.energy.2018.09.129.

[11] M. D. Aliyu and H. Chen, "Optimum control parameters and long-term productivity of geothermal reservoirs using coupled thermo-hydraulic process modelling," Renew. Energy, vol. 112, pp. 151-165, Nov. 2017, doi: 10.1016/j.renene.2017.05.032.

[12] H. Sekine and T. Mura, "Characterization of a penny-shaped reservoir in a hot dry rock.," J. Geophys. Res., vol. 85, no. B7, pp. 3811-3816, 1980, doi: 10.1029/JB085iB07p03811.

[13] H. Abé, H. Sekine, and Y. Shibuya, "Thermoplastic analysis of a cracklike reservoir in a hot dry rock during extraction of geothermal energy," J. Energy Resour. Technol. Trans. $A S M E$, vol. 105, no. 4, pp. 503-508, 1983, doi: 10.1115/1.3230963.

[14] T. W. Hicks, R. J. Pine, J. Willis-Richards, S. Xu, a. J. Jupe, and N. E. V. Rodrigues, "A hydro-thermo-mechanical numerical model for HDR geothermal reservoir evaluation," Int. J. Rock Mech. Min. Sci. Geomech. Abstr., vol. 33, no. 5, pp. 499-511, 1996, doi: 10.1016/0148-9062(96)00002-2.

[15] C. I. McDermott, A. R. L. Randriamanjatosoa, H. Tenzer, and O. Kolditz, "Simulation of heat extraction from crystalline rocks: The influence of coupled processes on differential reservoir cooling," Geothermics, vol. 35, no. 3, pp. 321-344, 2006, doi: 10.1016/j.geothermics.2006.05.002.

[16] Y. Jing, Z. Jing, J. Willis-Richards, and T. Hashida, "A simple 3-D thermoelastic model for assessment of the long-term performance of the Hijiori deep geothermal reservoir," $J$. Volcanol. Geotherm. Res., vol. 269, pp. 14-22, Jan. 2014, doi: 10.1016/j.jvolgeores.2013.10.012.

[17] K. M. Bower and G. Zyvoloski, "A numerical model for thermo-hydro-mechanical coupling in fractured rock," Int. J. Rock Mech. Min. Sci., vol. 34, no. 8, pp. 1201-1211, 1997, doi: 10.1016/S1365-1609(97)80071-8.

[18] M. D. Aliyu, H. Chen, O. Harireche, and C. D. Hills, "Numerical Modelling of Geothermal Reservoirs with Multiple Pore Media," in Proceedings, 42nd Workshop on Geothermal Reservoir Engineering Stanford University, Stanford, California, February 13-15, 2017 SGP-TR-212, 2017, pp. 1-12.

[19] H. Chen and M. D. Aliyu, "Numerical Modelling of Coupled Thermo-Hydraulic Problems for Long-Term Geothermal Reservoir," in VII International Conference on Computational Methods for Coupled Problems in Science and Engineering COUPLED PROBLEMS 2017 M. Papadrakakis, E. Oñate and B. Schrefler (Eds) NUMERICAL, 2017, pp. 234-243.

[20] M. D. Aliyu and R. A. Archer, "Numerical simulation of HDR geothermal energy reservoirs: A thermo-hydro-mechanical model," Geotherm. Resour. Counc. Trans., vol. 44, pp. 1145-1169, 2020.

[21] M. D. Aliyu and R. A. Archer, "Thermo-hydro-mechanical model of multifracture HDR geothermal reservoirs," Geotherm. Resour. Counc. Trans., vol. 44, pp. 403-428, 2020.

[22] M. D. Aliyu, "Hot dry rock reservoir modelling," University of Greenwich, 2018.

[23] T. Guo, F. Gong, X. Wang, Q. Lin, Z. Qu, and W. Zhang, "Performance of enhanced geothermal system (EGS) in fractured geothermal reservoirs with CO 2 as working fluid," Appl. Therm. Eng., vol. 152, no. February, pp. 215-230, 2019, doi: 10.1016/j.applthermaleng.2019.02.024. 
[24] M. D. Aliyu, H. Chen, and O. Harireche, "Finite element modelling for productivity of geothermal reservoirs via extraction well," in Proceedings of the 24th UK Conference of the Association for Computational Mechanics in Engineering 31 March-01 April 2016, Cardiff University, Cardiff, 2016, no. April, pp. 331-334.

[25] J. Willis-Richards, "Assessment of hdr reservoir stimulation and performance using simple stochastic models," Geothermics, vol. 24, no. 3, pp. 385-402, 1995, doi: 10.1016/03756505(95)00016-J.

[26] J. Willis-Richards, K. Watanabe, and H. Takahashi, "Progress toward a stochastic rock mechanics model of engineered geothermal systems," J. Geophys. Res. Solid Earth, vol. 101, no. B8, pp. 17481-17496, Aug. 1996, doi: 10.1029/96JB00882.

[27] S. C. Bandis, A. C. Lumsden, and N. R. Barton, "Fundamentals of rock joint deformation," Int. J. Rock Mech. Min. Sci., vol. 20, no. 6, pp. 249-268, 1983, doi: 10.1016/01489062(83)90595-8.

[28] N. Barton, S. Bandis, and K. Bakhtar, "Strength, deformation and conductivity coupling of rock joints," Int. J. Rock Mech. Min. Sci., vol. 22, no. 3, pp. 121-140, 1985, doi: 10.1016/0148-9062(85)93227-9.

[29] M. D. Aliyu and R. A. Archer, "Numerical simulation of multifracture HDR geothermal reservoirs," Renew. Energy, vol. 164, pp. 541-555, Feb. 2021, doi: 10.1016/j.renene.2020.09.085.

[30] M. D. Aliyu and R. A. Archer, "A thermo-hydro-mechanical model of a hot dry rock geothermal reservoir," Renew. Energy, vol. 176, pp. 475-493, 2021, doi: 10.1016/j.renene.2021.05.070.

[31] A. Ghassemi, A. Nygren, and A. Cheng, "Effects of heat extraction on fracture aperture: A poro-thermoelastic analysis," Geothermics, vol. 37, no. 5, pp. 525-539, Oct. 2008, doi: 10.1016/j.geothermics.2008.06.001.

[32] C. McDermott and O. Kolditz, "Geomechanical model for fracture deformation under hydraulic, mechanical and thermal loads," Hydrogeol. J., vol. 14, no. 4, pp. 485-498, 2006, doi: 10.1007/s10040-005-0455-4. 